\title{
Assessment of Cumulative Damage by Using Ultrasonic C-Scan on Carbon Fiber/Epoxy Composites Under Thermal Cycling
}

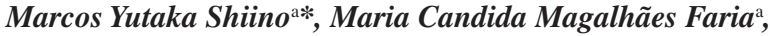 \\ Edson Cocchieri Botelho ${ }^{\mathrm{a}}$, Pedro Carlos de Oliveira ${ }^{\mathrm{b}}$ \\ ${ }^{a}$ Fatigue and Aeronautic Materials Research Group, Materials and Technology Department, \\ Guaratinguetá Faculty of Engineering, Universidade Estadual Paulista - UNESP, \\ Av. Ariberto Pereira da Cunha, 333, CEP 12516-410, Guaratinguetá, SP, Brazil \\ ${ }^{\mathrm{b}}$ Escola de Engenharia de Lorena - EEL, University of São Paulo - USP, \\ CP 116, CEP 12602-810, Lorena, SP, Brazil
}

Received: March 28, 2011; Revised: February 29, 2012

\begin{abstract}
In recent years, structural composites manufactured by carbon fiber/epoxy laminates have been employed in large scale in aircraft industries. These structures require high strength under severe temperature changes of $-56^{\circ}$ until $80^{\circ} \mathrm{C}$. Regarding this scenario, the aim of this research was to reproduce thermal stress in the laminate plate developed by temperature changes and tracking possible cumulative damages on the laminate using ultrasonic C-scan inspection. The evaluation was based on attenuation signals and the $\mathrm{C}$-scan map of the composite plate. The carbon fiber/epoxy plain weave laminate underwent temperatures of $-60^{\circ}$ to $80^{\circ} \mathrm{C}$, kept during 10 minutes and repeated for $1000,2000,3000$ and 4000 times. After 1000 cycles, the specimens were inspected by C-scanning. A few changes in the laminate were observed using the inspection methodology only in specimens cycled 3000 times, or so. According to the found results, the used temperature range did not present enough conditions to cumulative damage in this type of laminate, which is in agreement with the macro - and micromechanical theory.
\end{abstract}

Keywords: carbon fiber reinforcement plastics (CFRP), ultrasonic, thermal cycling

\section{Introduction}

Differential in the coefficient of thermal expansion (CTE) is a primary cause of thermal shock in composite materials, in which carbon fiber and polymeric matrix have a large difference in values, thus contributing to stresses at the interface, and moreover, a thermal shock which is related to rapid temperature changes, high temperatures, and stress gradients ${ }^{1,2}$. A very large CTE mismatch may result in debonding at the fiber/matrix interface and/or possible matrix cracking due to thermal stresses ${ }^{2,3}$. The fiber/matrix interface is likely to affect the overall mechanical behavior of fiber-reinforced composites. The performance of fiber reinforced composite is often controlled by the chemical adhesion at the fiber/matrix interface ${ }^{4}$.

Thermal cycling can be defined as changes in the temperature of the specimen when it reaches its equilibrium ${ }^{1}$. The temperature changes in a laminate generate stresses that can be predicted by Equation 1, one of the mostly used expressions. Simplifying Equation 1, considering a cross ply laminate, with subscription $\mathrm{L}$ as the reinforcement, and by cooling the composite will induce to a compressive stress $\left(\sigma_{L}\right)^{[1]}$.

$$
\sigma_{L}=\frac{\left(\alpha_{L}-\alpha_{H}\right) \Delta T E_{L} V_{H}}{V_{L}\left(\frac{E_{L}}{E_{H}}-1\right)+1}
$$

*e-mail: marcosshiino@yahoo.com.br where $\mathrm{L}$ and $\mathrm{H}$ indicate the lowest and the highest coefficient of thermal expansion (CTE); $\mathrm{V}$ is the volume of the components (matrix or fiber); $\mathrm{E}$ is the elastic modulus.

Replacing the compressive stress $-\sigma_{\mathrm{L}}$ into Equation 2, $\sigma_{H}$ becomes positive, i.e. tensile stress, with the matrix and fiber taking opposite directions as a result of the difference in CTEs. This behavior yields intraply concentration stress, which is developed because of the difference of the cure and the operational temperature that requires further investigation. The aforementioned situation involves several types of interface among them there are fiber, matrix or micromechanical features ${ }^{1-5}$. A better understanding of interfacial properties and a characterization of interfacial adhesion strength can help to evaluate the mechanical behavior of fiber reinforced composite materials. By adding some figures in Equation 1, considering a $\left[0^{\circ} / 90^{\circ} / 0^{\circ}\right]_{\mathrm{T}}$ laminate and $\Delta \mathrm{T}=100{ }^{\circ} \mathrm{C}$, a typical stress would be $15 \mathrm{MPa}^{[1]}$.

$$
\frac{\sigma_{H}}{E_{H}}-\frac{\sigma_{L}}{E_{L}}=\left(\alpha_{L}-\alpha_{H}\right) \Delta T
$$

Because of the large mismatch in the CTE of the composite components, microcracking is prone to appear when there are temperature changes ${ }^{5}$. The concern about the thermal fatigue phenomena that involves changes in thermal environment has been a source of study due 
to failures that occur in static applications, e.g. failure in kitchen sinks which alternate hot and cold water ${ }^{6}$. In multiaxial composites, the difference in ply orientation and a mismatch between materials CTE leads to thermal stresses, which can be predicted by a macromechanical analysis. By temperature cycling, the laminate behavior can be analyzed as if performing mechanical fatigue test but under multiaxial load, therefore degrading the stiffness of the laminate ${ }^{7-9}$.

The above discussions clearly show stresses applied in the laminate from temperature cycling. According to a micromechanical approach, stresses mainly are developed into the matrix and the severity depends on the voids density ${ }^{10}$. For epoxy resins, the crack density is usually higher than in a thermoplastic matrix, like $\mathrm{PEEK}^{10}$.

Defects, like voids or microcracks, can be monitored by non-destructive tests which have usually been employed in previous studies. A common and fast assessment has been conducted using the ultrasonic technique, which detects voids and bubbles inside the matrix ${ }^{11,12}$. The method makes it possible to track the progression of inward cracks. The accuracy depends on the transducer frequency and the minor crack size can be estimated by using Equation $3^{[12-15]}$.

$d=\frac{\lambda}{2}$

where $\mathrm{d}$ is the crack size and $\lambda$ is the wave length produced by the ultrasonic transducer.

In order to evaluate a real application of composite materials in aircraft components, the thermal cycling was used as a common manner to simulate real aircraft operational conditions ${ }^{15}$. Regardless of the aim of this research, the standard MIL-HDBK-17-1F ${ }^{[16]}$ was taken into account to test the laminate under a temperature envelop, requested by aircraft development programs. This experimental work investigation was conducted in order to non-destructively evaluate, using ultrasonic inspection, the carbon fiber/epoxy laminate integrity every 1000 temperature cycles $\left(-60\right.$ to $\left.80{ }^{\circ} \mathrm{C}\right)$ until it reached 4000 cycles.

\section{Experimental Procedure}

\subsection{Materials and processing}

The intermediate modulus carbon fiber/epoxy composites were manufactured via autoclave processing. HexPly ${ }^{\circledR}$ F155 prepreg fabric tapes (Plain Weave), supplied from Hexcel Company, were stacked in a way to keep the weft and warp fiber pointing at the same direction, accounting for 10 plies and $3.30 \mathrm{~mm}$ thickness.

Cure preparation primarily involves the bagging of the preformed part and the cutting and placement of many ancillary materials. After the lay-up process, the laminate is bagged under vacuum. The laminate is then placed in an autoclave in order to cure the resin system. During the cure cycle, a low heat ratio of $2.5^{\circ} \mathrm{C} / \mathrm{min}$ was employed in order to remove the bubbles until it reaches $121^{\circ} \mathrm{C}$, kept for 180 minutes. A constant pressure of $0.69 \mathrm{MPa}$ and the vacuum being at $0.083 \mathrm{MPa}$ were employed during the entire process.

\subsection{Thermal cycle conditioning}

The thermal cycling was performed in an Envirotronics device (model TVS.5-2-2-2-AC), known as Two Zone Vertical Thermal Shock, which is specifically for the aforementioned purpose. A vertical elevator changed the temperature zone ranging from -60 to $80^{\circ} \mathrm{C}$, and it was kept for 10 minutes in each zone prior to reaching the equilibrium. It was cycled 1000 times and then, the laminate integrity was inspected using an ultrasonic test. The procedure was repeated until it reached 4000 cycles using a duplicate specimen.

\subsection{Ultrasonic test}

The ultrasonic inspection was performed by using the pulse-echo mode Microscopy Inspection Acoustic System-Model PSS-600, which applied the software MUIS-32 for data acquisition, and immersing the duplicate specimen (specimen 1 and 2) in a water bath. It was kept a $127 \mathrm{~mm}$ distance between the flat specimen and the transducer to achieve an optimum performance. The results were provided in a C-scan map or an A-scan graph, which can detect discontinuities in the composites, e.g. resin-rich regions, voids or cracks.

A probe range can be employed from 2.25 to $10 \mathrm{MHz}$. In this research, the $10 \mathrm{MHz}$ probe was more suitable due to being the easiest assessment to identify the defects. The A-scan graph, Figure 3, calibrated the patterns of typical structural composite peaks (reference-without defects), and the difference between the reference peak and the other peaks is referred as the attenuation signal. In the A-scan graph, any change in the height of the backwall echo, detailed in A-Figure 3, stands for imperfections through the laminate thickness. The intensity of the attenuation signals can inform what type of defect it might have.

Each point of the laminate has a characteristic A-scan signal that formed the C-scan map after scanning the entire laminate with a $150 \mathrm{~mm} / \mathrm{min}$ speed ratio. The referred map shows the backwall echo produced by the A-scan, which shows any flaws along the thickness.

The first ultrasonic assessment was performed after the specimens had been cycled 1000 times, and all the critical attenuation points, regarded as a potential defect, were tracked after each 1000 cycles.

Figure 1 represents the color scale of the attenuation signal employed to evaluate the C-scan maps, where $0 \%$ represents high attenuation or region of low density, which is proportional to the acoustic impedance, and $100 \%$ of the entire echo returned, which means that there is a region without void or high density.

\section{Results and Discussion}

Figures $2 \mathrm{a}$ and $2 \mathrm{~b}$ depict the first map of specimens 1 and 2 (duplicate), respectively. Detail A of Figure 3 presents the background echo of the A-scan graph for these specimens after being cycled 1000 times, and detail B shows the surface echo. The distance between these two peaks represents the laminate thickness in $\mu$ s. Those background echoes were monitored by using gate 1, also depicted in Figure 3, using $15 \%$ of the attenuation level in blue color (every eventually 


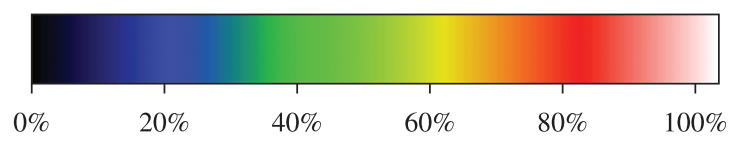

Figure 1. Color scale for C-scan maps.

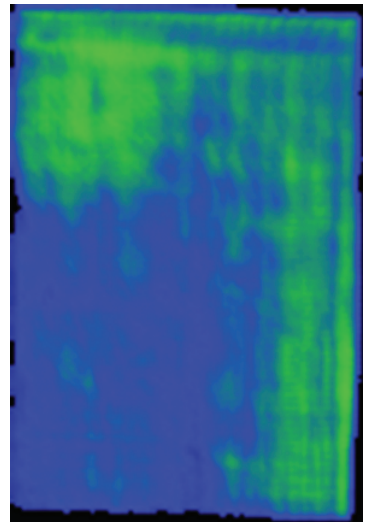

(a)

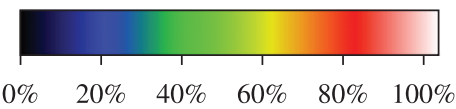

Figure 2. C-scan maps after 1000 cycles: a) laminate 1; b) laminate 2.

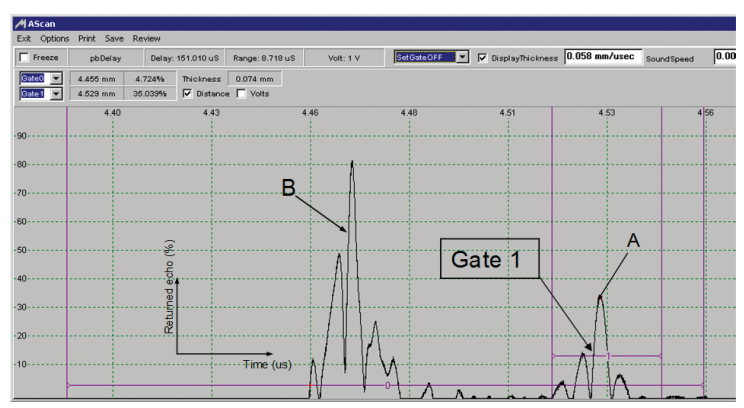

Figure 3. A-scan graph of laminate 1 after 1000 cycles.

drop or raise was considered as a potential defect). As it can be observed from these results, both laminates presented a similar level of attenuation. In blue color, it is represented the high attenuation, which means a lack of resin when compared to green-colored regions (region of low attenuation, around 55\%). Those different attenuations can not be considered as defects so far, like delaminations or dry spots. The discrepancies in attenuation signals of the laminates may be attributed to variations of the applied pressure during the manufacturing process, which did not keep the same impregnation along the plate.

Figure 4 presents the ultrasonic results from the specimens after being cycled 2000 times. As it can be observed from these maps, after 2000 cycles, the laminates remained in the same condition comparing to the specimens submitted to 1000 cycles, but only one black region (with high attenuation signal) was found in laminate 1 (Figure 4a, detailed by the arrow). The attenuation signal in laminate 2 (Figure 4b) slightly changed, but it can not be considered as a crack nucleation, which can be well represented as a sharp dot.

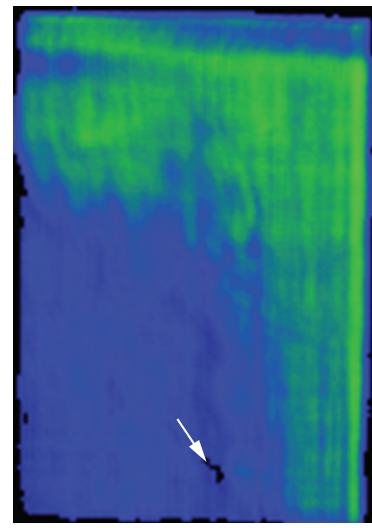

(a)

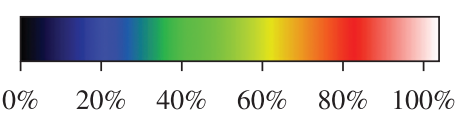

Figure 4. C-scan maps after 2000 cycles: a) laminate 1; b) laminate 2.

After 3000 cycles, the C-scan maps also presented insignificant changes in the attenuation signal. Both of them presented acceptable scatterings in attenuation signals explained by deviations in the laminate positioning in the bath (Figure 5). Regarding this fact, it is improbable to keep the laminate in the same plane of the previous scan, and this change modifies the attenuation of the whole composite.

After 4000 cycles, significant changes are observed in Figures $6 \mathrm{a}$ and $6 \mathrm{~b}$. For both laminates, the regions considered as being resin-rich tended to disappear where predominantly blue attenuation areas were found, as detailed in Figure 6a-detail 1. An explanation for this phenomenon can be associated to a few changes in ply positions that remained in a different plane, as compared to other maps. Nonetheless, it was an overall change that did not demonstrate any signal of crack nucleation or delamination. Otherwise, the signal can be totally lost by sound dispersion and sharp black dots would appear.

Despite the slight changes in the overall attenuation signals from cycle to cycle, it may still raise some concern in the reader's mind. However none of them represented sharp attenuations that are usually associated with cracks or delaminations. If it were so, it could be tracked in the subsequent scans, due to the well-known fatigue crack propagation, which is developed every each cyclic load imposed to the specimen ${ }^{17,18}$.

Another feature that is worth being mentioned regarding the few changes in the C-scan maps is the symmetry of this laminate that contributed to develop low thermal stresses during the thermal cycling.

The summary of the changes in the attenuation signal is presented in Table 1. These values were counted using the image analysis processing software. This program enables the segregation of the area of interest and provides the area fraction. According to the above discussions, major changes in the composites' attenuation signal were between 3000 cycles and 4000 cycles. The measured areas of the blue attenuation signal is a manner for a better comparison among them, and also to confirm what was stated in previous 


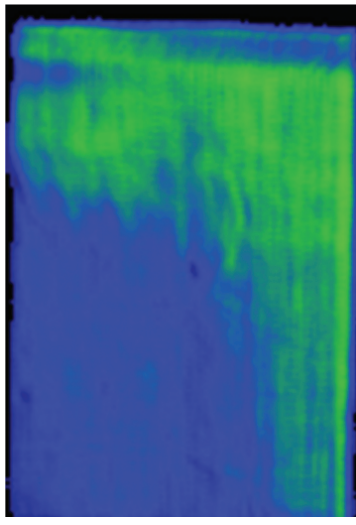

(a)

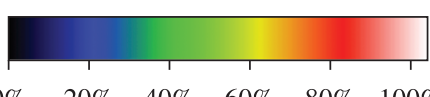

$\begin{array}{llllll}0 \% & 20 \% & 40 \% & 60 \% & 80 \% & 100 \%\end{array}$

Figure 5. C-scan maps after 3000 cycles: a) laminate 1; b) laminate 2.

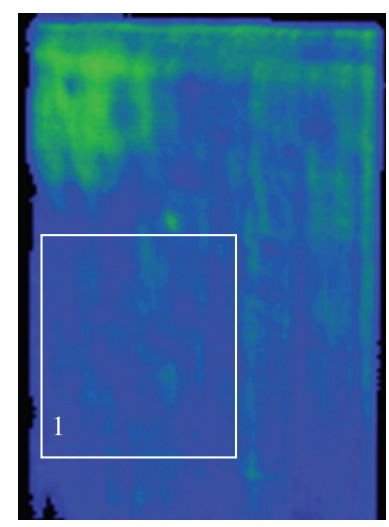

(a)

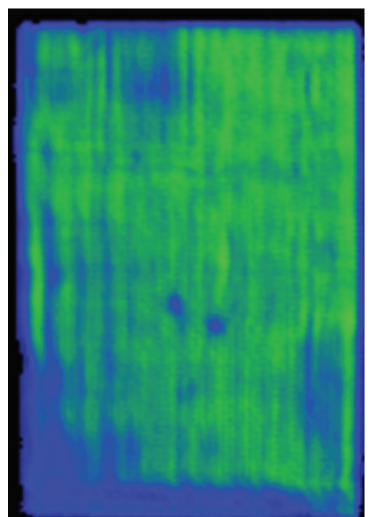

(b)

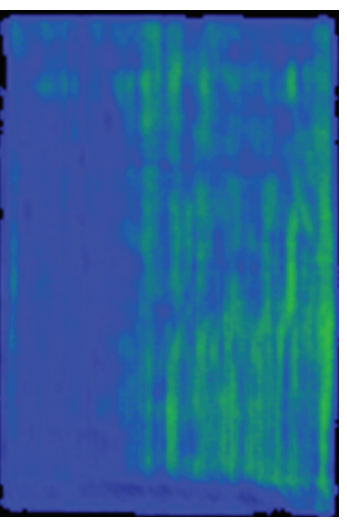

(b)

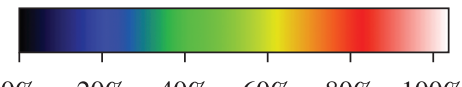

$\begin{array}{llllll}0 \% & 20 \% & 40 \% & 60 \% & 80 \% & 100 \%\end{array}$

Figure 6. C-scan map 4000 cycles: a) laminate 1; b) laminate 2.

Table 1. Total fraction area of the blue color attenuation.

\begin{tabular}{ccc}
\hline Cycles & $\begin{array}{c}\text { Blue area } \\
(\mathbf{8 0 \%} \text { attenuation) } \\
\text { laminate 1 }(\%)\end{array}$ & $\begin{array}{c}\text { Blue area } \\
(\mathbf{8 0 \%} \text { attenuation) } \\
\text { laminate 2 }(\%)\end{array}$ \\
\hline 1000 & 60.59 & 22.08 \\
2000 & 60.36 & 28.04 \\
3000 & 58.61 & 30.67 \\
4000 & 86.91 & 86.64 \\
\hline
\end{tabular}

paragraphs. Laminate 1 progressively reduced the blue attenuation areas until 4000 cycles were reached. Afterward, the blue attenuation signal area increased, but the green attenuation signals were spread, where blue colors were predominantly found in other inspections before this one.

According to the macromechanical theory ${ }^{3}$, no residual stresses will be introduced in a symmetric laminate. Despite the fact that this is a fabric, a comparison can be made as the symmetry was maintained when laying up the plies.
Table 2. Material properties of the components.

\begin{tabular}{ccc}
\hline Material & Tensile modulus $(\mathbf{G P a})$ & $\mathbf{C T E}\left({ }^{\circ} \mathbf{C}^{-\mathbf{1}}\right)$ \\
\hline Fiber & 231 & $-1.6 \times 10^{-6}$ \\
Matrix & 3.24 & $50 \times 10^{-6}$ \\
\hline
\end{tabular}

When the experiments were performed, no restrictions were applied, thus the resultant moment and the applied forces to the laminate were zero $(\{N\}=\{0\}$ and $\{M\}=\{0\})$. Assuming these conditions, the resultant forces due to temperature variations can be calculated using Equation 4, by the sum of the $\mathrm{k}^{\text {th }}$ layer in a multilayered laminate.

$\{N\}^{T}=\sum_{k=1}^{N}\left(h_{k}-h_{k-1}\right)[\bar{Q}]_{k}\{e\}_{k}$

The total deformation caused by temperature variations can be found by the results of Equation 4. The results in turn are introduced in Equation 5 for each ply in order to evaluate the stress. The final solution is illustrated in Equation 6 for a $0^{\circ}$ ply. In addition, considering $E_{1}>>E_{2}$ and $\lambda_{2}>>\lambda_{2}$ ( 1 and 2 being the local coordinate systems), a simplification can be conducted yielding to Equation 7.

$$
\{\sigma\}_{k}=[\bar{Q}]_{k}\left\{\{\varepsilon\}^{0}-\{e\}_{k}\right\}
$$

$$
\left\{\begin{array}{l}
\sigma_{x}^{R} \\
\sigma_{y}^{R} \\
\tau_{S}^{R}
\end{array}\right\}_{0^{0}}=\Delta T\left(\alpha_{2}-\alpha_{1}\right) \frac{E_{1} E_{2}}{E_{1}+E_{2}\left(1+v_{12}\right)}\left\{\begin{array}{c}
1 \\
-1 \\
0
\end{array}\right\}
$$

The solution of Equation 7 means that the residual stress is dominant by the matrix mechanical properties. Conducting the same procedure for the $90^{\circ}$ plies, the signal of the residual stress (left hand side of Equation 7) will change for the $\mathrm{x}$ and $\mathrm{y}$ directions yielding to zero residual stress for the laminate when accounting for all plies.

$\left\{\begin{array}{c}\sigma_{x}^{R} \\ \sigma_{y}^{R} \\ \tau_{S}^{R}\end{array}\right\}_{0^{0}}=\Delta T \alpha_{2} E_{2}\left\{\begin{array}{c}1 \\ -1 \\ 0\end{array}\right\}$

From the micromechanical approach, the compressive stress $\left(\sigma_{L}\right)$ was calculated based on the properties of the composites components (matrix and fiber), illustrated on Table 2, and Equation 1. The worst case scenario happened when the laminate was at $-60{ }^{\circ} \mathrm{C}$. At this temperature, $-19.17 \mathrm{MPa}$ of compressive stress acted on fibers, meanwhile, the tensile stress acted on the matrix. This tensile stress did not cause matrix degradation process by the estimated cyclic loading, according to the ultrasonic inspection.

\section{Conclusion}

According to the results obtained in this work, microstructural changes could be observed using the ultrasonic inspection in the laminates cycled 3000 times, or so.

This study also verified a low void content in the composites as it can generate cracks, easily detectable by $\mathrm{C}$-scan method, due to the influence of the temperature changes on the entrapped gases (thermal expansion). 
From the macromechanical model applied to temperature of $-60{ }^{\circ} \mathrm{C}$, it resulted of theoretical stresses below the necessary one in order to nucleate cracks, thus, not reaching minimum stresses to modify the features of the C-scan maps from a health laminate.

The quality inspection methodology appears to have low accuracy, as the tests depended on the perfect position of the laminate in the water bath. However, for the crack detection purpose, the ultrasonic inspection is reliable, and it offers a complete diagnosis regarding the position of the crack (in-plane and out-of-plane) and size.

\section{Aknowledgements}

The authors would like to acknowledge the financial support from FAPESP (processes numbers 2005/54358-7, 2006/02121-6, 2009/04123-4 and 2011/01937-0) and the Foundation for Scientific and Technological Development for the English review.

\section{References}

1. Hancox NL. Thermal effects on polymer matrix composites: Part 1. Thermal Cycling. Materials \& Design. 1998; 19(3):85-91. http://dx.doi.org/10.1016/S0261-3069(98)00018-1

2. Dimitrijevic M, Posarac M, Majstorovic J, Volkov-Husovic $\mathrm{T}$ and Matovic B. Behavior of Silicon carbide/ cordierite material after cyclic thermal shock. Ceramics International. 2009; 35(3):1077-1081. http://dx.doi. org/10.1016/j.ceramint.2008.04.029

3. Jones RM. Mechanics of Composite Materials. Philadelphia: Taylor and Francis; 1999.

4. Ray BC. Thermal shock on interfacial adhesion of thermally conditioned glass fiber/epoxy composites. Materials Letters. 2004; 58(16):2175-2177.

5. Chawla N, Chawla KK, Koopman M, Patel B, Coffin C and Eldridge JI. Thermal-shock behavior of a Nicalon fiber-reinforced hybrid glass-ceramic composite. Composites Science and Technology. 2001; 61(13):1923-1930. http:// dx.doi.org/10.1016/S0266-3538(01)00096-3

6. Capela C, Costa JD, Antunes F and Ferreira JM. Thermal fatigue assessment of components made with particulate polymer composites. Theoretical and Applied Fracture Mechanics. 2004; 42(2):171-181. http://dx.doi.org/10.1016/j. tafmec.2004.08.008

7. Lafarie-Frenot MC and Roquie S. Influence of oxidative environments on damage in C/epoxy laminates subjected to thermal cycling. Composites Science and Technology. 2004; 64(10-11):1725-1735. http://dx.doi. org/10.1016/j.compscitech.2004.01.005

8. Lafarie-Frenot MC, Ho NQ and Bellenger V. Comparison of damage development in C/epoxy laminates during ageing or thermal cycling. Composites Science and Technology. 2006; 37(4):662-671.

9. Huang YD, Hort N, Dieringa H, Maier P and Kainer KU. Investigations on thermal fatigue of aluminun - and magnesium - alloy based composites. International Journal of

Fatigue. 2006; 28(10):1399-1405. http://dx.doi.org/10.1016/j. ijfatigue.2006.02.038

10. Hartwig G, Hubner R, Knaak S and Pannkoke C. Fatigue behaviour of composites. Cryogenics. 1998; 35(1):75-78. http:// dx.doi.org/10.1016/S0011-2275(97)00113-6

11. Trias D, Garcia R, Costa J, Blanco N and Hurtado JE. Quality control of CFRP by means of digital image processing and stastistical point pattern analysis. Composites Science and Technology. 2007; 67(11-12):2438-2446. http://dx.doi. org/10.1016/j.compscitech.2006.12.023

12. Nesvijski EG. Some aspects of ultrasonic testing of composites. Composite Structures. 2000; 48(1-3):151-155.

13. Dinckinson LP and Fletcher NH. Acoustic detection of invisible damage in aircraft composite paneld. Applied Acoustics. 2009; 70(1):110-119.

14. Andreucci R. Ensaio por ultra-som. Abende; 2003.

15. D’Orazio T, Leo M, Distante A, Guaragnella C, Pianese $\mathrm{C}$ and Cavaccini C. Automatic ultrasonic inspection for internal defect detection in in composite materials. $N D T$ \& E Internacional. 2008; 41(2):145-154. http://dx.doi. org/10.1016/j.ndteint.2007.08.001

16. United States. Composite Materials Handbook. Department of Defens; 2002. MIL-HDBK-17-F1. v. 1. Polymer matrix composites guidelines for characterization of structural materials.

17. Wu S and Xu W. Short thermal fatigue crack propagation behavior of alumina short fibre reinforced aluminum matrix composites. Journal of Material Science. 2000; 35(1):5347-5351. http:// dx.doi.org/10.1023/A:1004846929069

18. Kelkar AD, Teta JS and Bolick R. Structural integrity of aerospace textile composites under fatigue loading. Materials Science and Engineering B. 2006; 132(1-2):79-84. http:// dx.doi.org/10.1016/j.mseb.2006.02.033 